\title{
METODOLOGIA PARA GESTÃO DE RISCO NA IMPORTAÇÃO DE INSUMOS FARMACÊUTICOS NO ESTADO DO PARANÁ
}

\section{METHODOLOGY ON RISK MANAGMENT OF PHARMACEUTICAL INPUTS IMPORTATION IN THE PARANÁ STATE}

\author{
Rafael Zannin', Eduardo Marques Trindade ${ }^{2}$
}

1 - Discente do Curso de Mestrado dos Institutos Lactec. Curitiba - PR.

2 - Docente do curso de mestrado dos Institutos Lactec. Curitiba - PR.

Autor para correspondência: rafael.zannin@lachemicals.com.br

\section{RESUMO:}

O processo de importação no Estado do Paraná é complexo e as empresas farmacêuticas dependem de insumos ou produtos importados para suas operações. As etapas do processo de importação devem seguir normas internacionais e nacionais reguladas pela Receita Federal e outros órgãos estaduais e municipais. Existem fatores a serem gerenciados e executados para realizar o monitoramento das etapas do processo de importação, como, habilitação da empresa, fatores logísticos, licenças de importação, sistemas informatizados, avarias nas cargas, terceiros e controles fiscais. Os desafios atuais concentram esforços na compreensão da legislação aduaneira e das fases de um projeto de importação a fim de obter o menor prazo possível nas etapas no menor custo. Assim, conduziu-se uma pesquisa das normas internacionais e nacionais, utilizando-se do fluxograma das etapas de um processo de importação da Receita Federal, de uma matriz de risco de probabilidade e impacto para avaliação dos resultados. Foram coletadas informações de importadores e prestadores de serviço no Estado do Paraná no ano de 2018, utilizando-se de um questionário e entrevistas que apresentaram informações reais das empresas e de suas importações, prazos, gestão operacional e principais pontos críticos. As informações obtidas permitiram avaliar o impacto dos riscos e oportunidades nos processos de importação parametrizados em canal vermelho e avaliar o impacto dos riscos nos processos de importação desde a abertura da empresa importadora até a nacionalização de uma importação.

Palavras-chave: Gestão de riscos, importação, insumos, matriz de risco, custos.

\section{ABSTRACT:}

The import process in the State of Paraná is complex and pharmaceutical companies depend on imported inputs or products for their operations. The import process stages must follow international and national standards regulated by the Federal Revenue (Receita Federal) and other state and municipal bodies. There are factors to be managed and executed to monitor the stages of the import process, such as company qualification, logistical factors, import licenses, computer systems, cargo damages, third parties and tax controls. The current challenges focus their efforts on understanding the customs legislation and the phases of an import project in order to obtain the stages shortest possible time and lowest cost. Therefore, an international and national standards survey was conducted, using the stages flowchart of an import process from the Federal Revenue (Receita Federal), of a probability and impact risk matrix for a results evaluation. Information was collected from importers and service providers in the State of Paraná in 2018, using a questionnaire and interviews that presented real information about the companies and their imports, deadlines 
operational management and main critical points. The information obtained made it possible to assess the risk impact and opportunities in the import processes parameterized in red channel and to assess the risk impact in the import processes from the opening of the importing company to the nationalization of an import.

Keywords: Risk management, import, inputs, risk matrix, costs.

\section{INTRODUÇÃO}

O Comércio internacional começou a ser regulamentado após a Segunda Guerra Mundial para promover a cooperação do livre comércio entre países, sendo que atualmente a Organização Mundial do Comércio (OMC) é quem faz esse papel regulatório (VANGRASSTEK, 2013). O Brasil faz parte da OMC e no ano de 2018 participou com 1,1\% de todo o comércio mundial, representando U\$181,2 bilhões de dólares americanos sendo a nona maior economia mundial (Banco Mundial, 2019). Já o Estado do Paraná participou com US\$12,3 bilhões de dólares americanos, representando 6,8\% das importações do país (COMEXSTAT, 2019), sendo o quarto maior importador entre os estados.

Além dos acordos internacionais, o Paraná deve atender a legislação Federal através do Decreto $n^{\circ} 6.759$ de 5 de fevereiro de 2009, que regulamenta a administração das atividades aduaneiras, fiscalização, o controle e a tributação das operações de comércio exterior, somado à legislação estadual e municipal.

O desenvolvimento dos projetos de importação é de extrema importância para a tomada de decisão por parte das empresas farmacêuticas, pois a carência de gerenciamento de riscos na cadeia de suprimentos pode gerar grandes perdas, citando a Pfizer com US\$2,8 bilhões de dólares respectivamente em 2017 (Oliveira, 2017).

A primeira fase para que uma empresa possa importar é sua habilitação junto a Receita Federal através do Rastreamento da Atuação de Intervenientes Aduaneiros (RADAR). Após possuir o RADAR, a empresa estará autorizada a operar no Sistema Integrado de Comércio Exterior (SISCOMEX), que é o sistema do Governo para efetuar o registro de uma importação. Tal registro deve tomar como referência o fluxograma da Receita Federal que determina todas as etapas que o importador deve cumprir (Receita Federal, 2015 a) conforme FIGURA 1: 


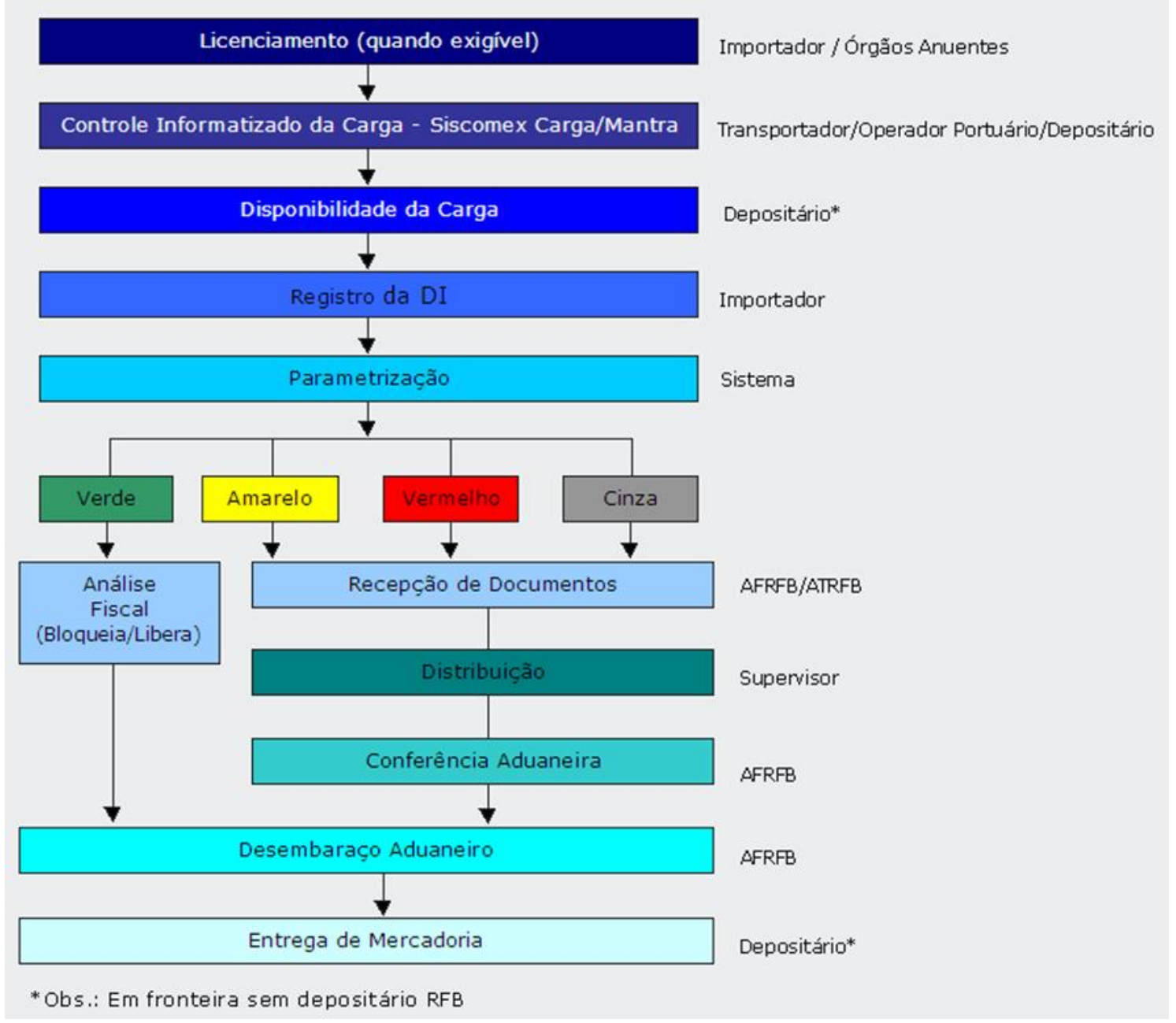

FONTE: Receita Federal (2015 a)

LEGENDA: AFRFB - Auditor-Fiscal da Receita Federal

ATRFB - Analista Tributário da Receita Federal

RFB - Receita Federal do Brasil

FIGURA 1 - Fluxograma das etapas do processo de importação da Receita Federal.

Em cada uma das etapas, existem variáveis como a classificação fiscal do insumo a ser importado, tributos, licenças de importação, documentos, contratação de agentes de carga, despachantes aduaneiros e controles fiscais. Essas variáveis podem aumentar os prazos e custos de um projeto de importação e devem ser avaliadas com a finalidade de prever os possíveis riscos e oportunidades antes do início do projeto. Para que fosse possível avaliar as variáveis, este trabalho fundamentou-se no Guia de Gerenciamento de Projetos “Project Management Body Of Knowledge” (PMBOK®), aplicando as boas práticas 
de gerenciamento de riscos (PMI, 2017) através da medição da probabilidade de impacto dos riscos e oportunidades com a utilização de uma matriz.

O objetivo deste trabalho foi analisar os dados obtidos em cada uma das etapas, considerando os riscos e oportunidades a serem gerenciados e avaliar a probabilidade e impacto dos riscos em cada uma das etapas, desde a abertura da empresa até a nacionalização de uma importação.

\section{METODOLOGIA}

Este estudo foi realizado em quatro etapas para a construção da metodologia de gestão de riscos em processos de importação por empresas farmacêuticas no Estado do Paraná.

$\mathrm{Na}$ primeira etapa foi identificado as regulamentações internacionais e nacionais disponíveis e com estas regulamentações, foi possível determinar a abrangência do trabalho e delimitar o planejamento de um projeto de importação no Paraná.

$\mathrm{Na}$ segunda etapa foi feita a pesquisa de campo com importadores por meio de questionário "on-line" do Google "Forms" e entrevista com comissárias de desembaraço aduaneiro do Estado do Paraná. Com essas informações, foi obtido do mercado as informações necessárias para identificação e priorização dos riscos e prazos de um projeto de importação.

O escopo do questionário foi exploratório, com objetivo de obtenção de dados das importações reais dos importadores em 2018, com a finalidade de colaborar com a definição dos problemas de pesquisa relacionados aos processos de importação, definição de foco, compreensão do comportamento e levantamento de hipóteses (PINHEIRO et. al., 2011 a). Os objetivos do questionário foram definidos com base na legislação aduaneira e no fluxograma das etapas do processo de importação estipulado pela Receita Federal.

Com relação à entrevista, foi realizada no domicílio ou local de trabalho do entrevistado com a finalidade de conseguir mais tempo com o despachante aduaneiro, já que a entrevista possuía muitas perguntas com necessidade de reflexão ou busca por banco de dados dos clientes importadores para as respectivas respostas (PINHEIRO et. al., 2011 b).

$\mathrm{Na}$ terceira etapa foi realizado, com base no fluxograma da Receita Federal, um fluxograma das etapas de importação incrementado de processos decisórios, para que empresas farmacêuticas que desejam importar possam entender a sequência das etapas 
de um projeto de importação a serem executadas.

E na quarta etapa foi criada uma matriz de probabilidade e impacto para avaliação das oportunidades e dos riscos com base no Guia de Gerenciamento de Riscos PMBOK®.

\section{RESULTADOS E DISCUSSÃO}

Identificadas as regulamentações internacionais e nacionais descritas na introdução, observou-se a necessidade de uma forma mais didática de acompanhamento de um projeto de importação.

Conforme verificado na FIGURA 1, a Receita Federal disponibiliza de forma simplificada um fluxograma das etapas de um projeto de importação, porém sem processos decisórios. Foi observado, conforme veremos mais a frente, que a falta dos processos decisórios nas etapas do processo, dificulta o correto planejamento de um projeto de importação, pois a falta dessas informações impossibilita a determinação de prazos e custos.

Para que fosse possível aplicar os processos decisórios no fluxograma da Receita Federal, foi utilizado um questionário on-line enviado aos importadores do Estado do Paraná. Este questionário obteve os processos pelos quais os importadores devem cumprir e também apontaram os pontos críticos na gestão de riscos. Além do questionário on-line, foi realizada uma entrevista com despachantes aduaneiros no Estado do Paraná para confirmação dos dados obtidos no questionário.

Com estas informações, foi desenvolvido um fluxograma das etapas de um projeto de importação com processos decisórios, conforme FIGURAS 2, 2.1, 2.2, 2.3 formatado para empresas farmacêuticas que desejam importar insumos, permitindo o correto planejamento das etapas e a sequência de operações a serem executadas em um projeto de importação, tomando como base o fluxograma da Receita Federal.

Esse fluxograma é divido em quatro módulos, sendo o primeiro deles a abertura da empresa, obtenção de registros e a negociação junto ao exportador. O segundo módulo apresenta questões fiscais e tributárias e a contratação de terceiros, como despachantes aduaneiros e agentes de carga. Já no terceiro módulo é possível identificar a nacionalização da importação e os canais de fiscalização, verde, amarelo, vermelho e cinza. E por último, as operações burocráticas e tributárias para liberação do processo de importação de acordo com o decreto 6.759 do Regulamento Aduaneiro. 


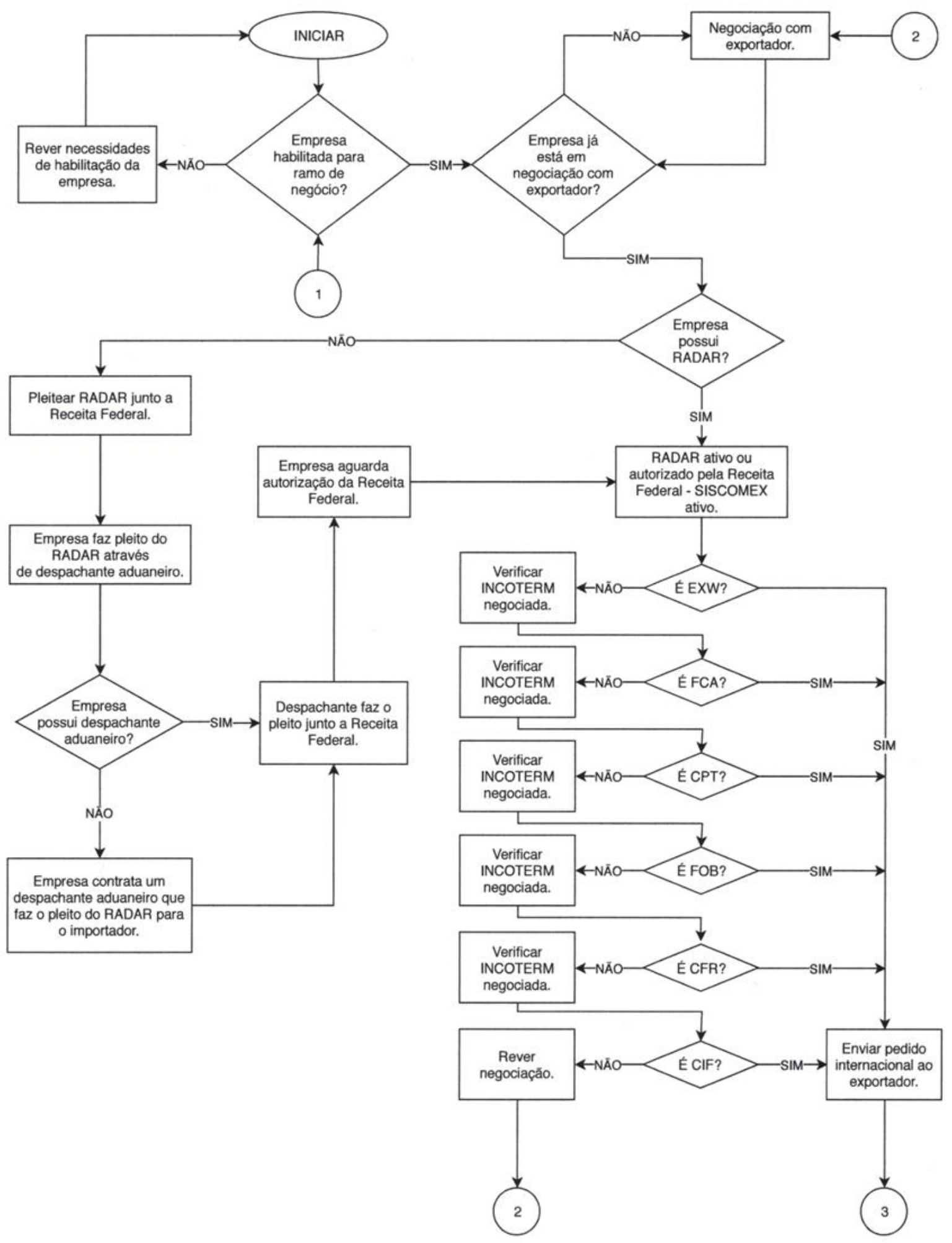

FONTE: O autor (2019)

FIGURA 2 - Fluxograma das etapas do processo de importação com processos decisórios, módulo 1. 


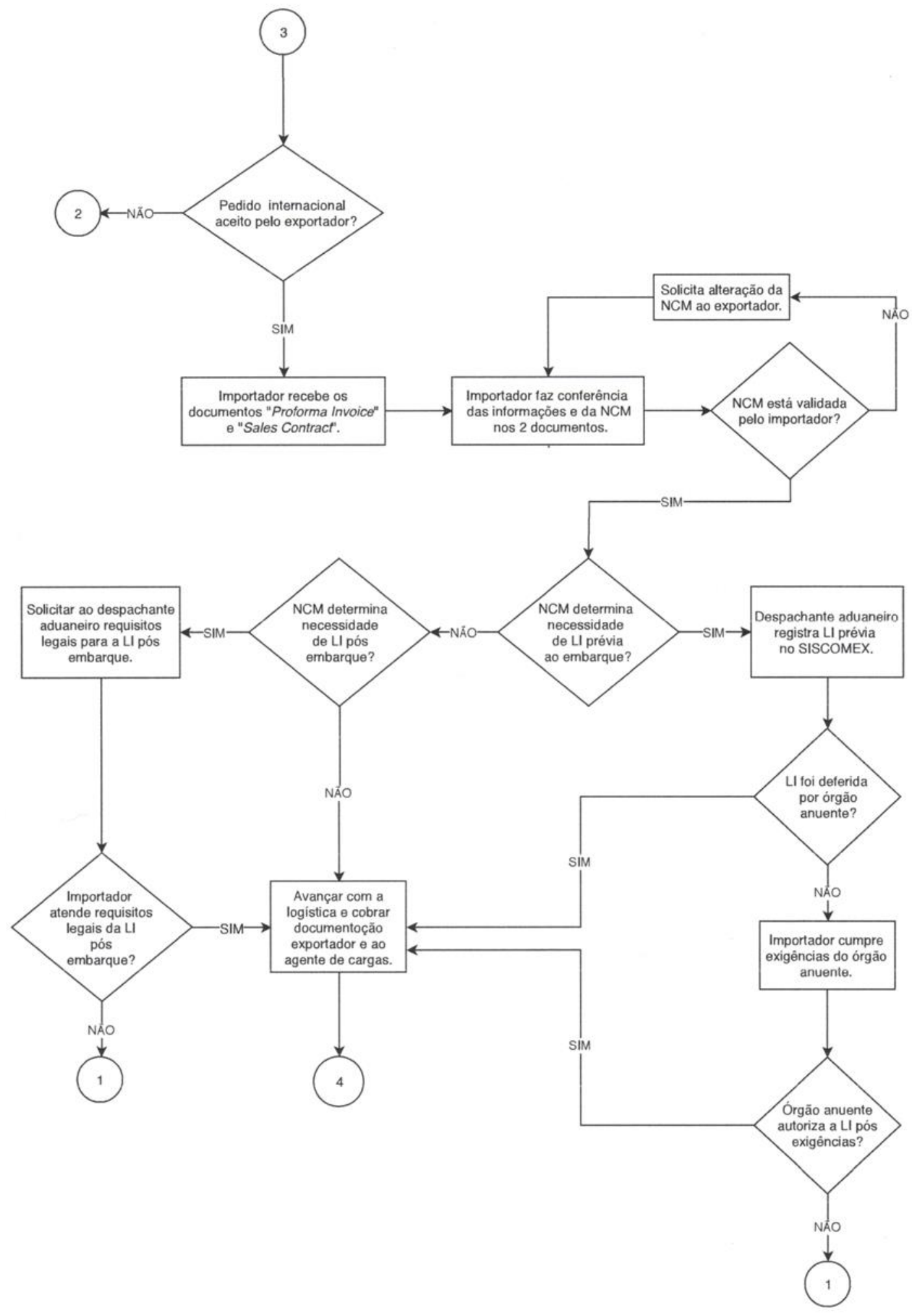

FONTE: O autor (2019)

FIGURA 2.1 - Fluxograma das etapas do processo de importação com processos decisórios, módulo 2. 


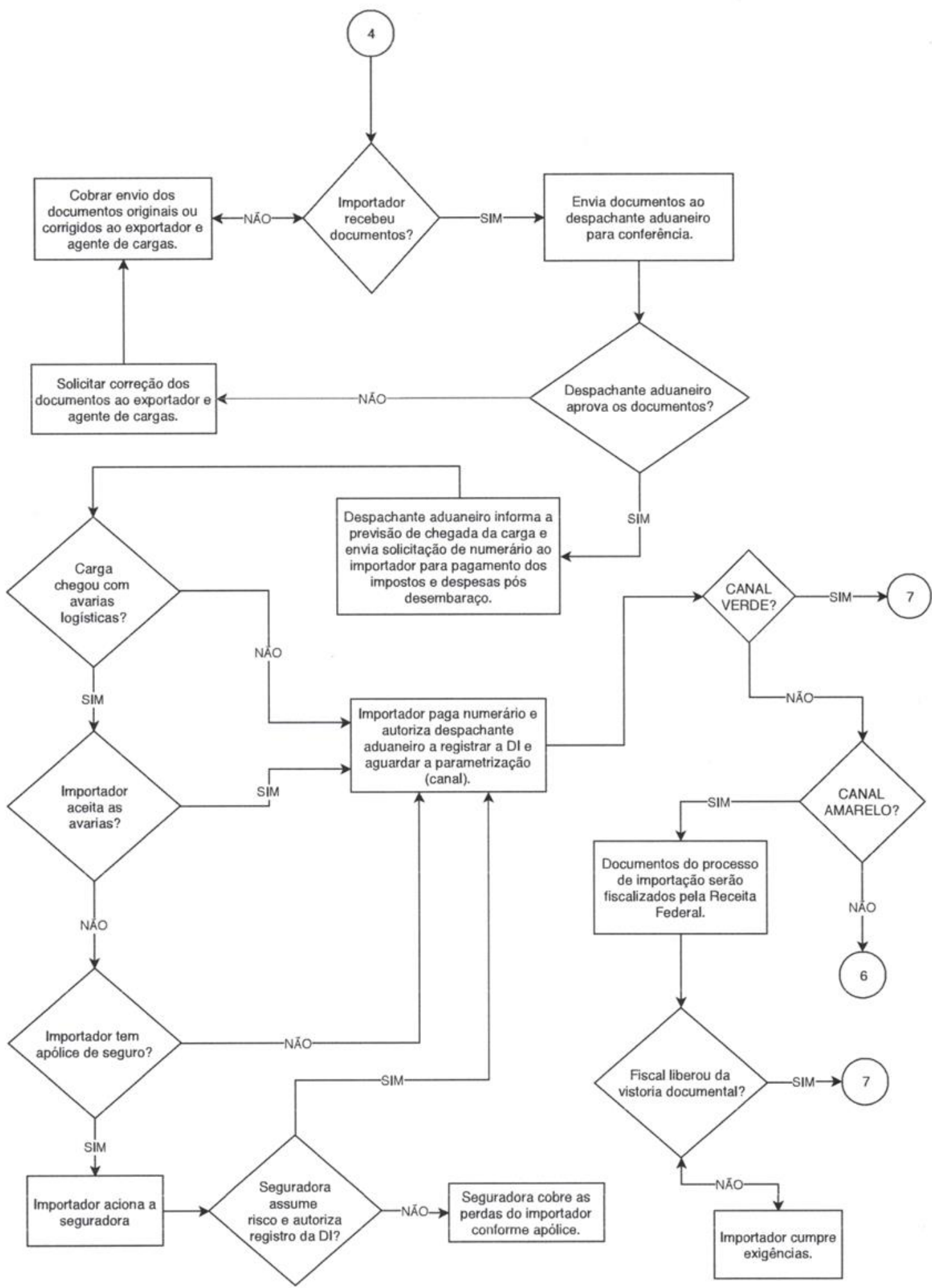

FONTE: O autor (2019)

FIGURA 2.2 - Fluxograma das etapas do processo de importação com processos decisórios, módulo 3. 

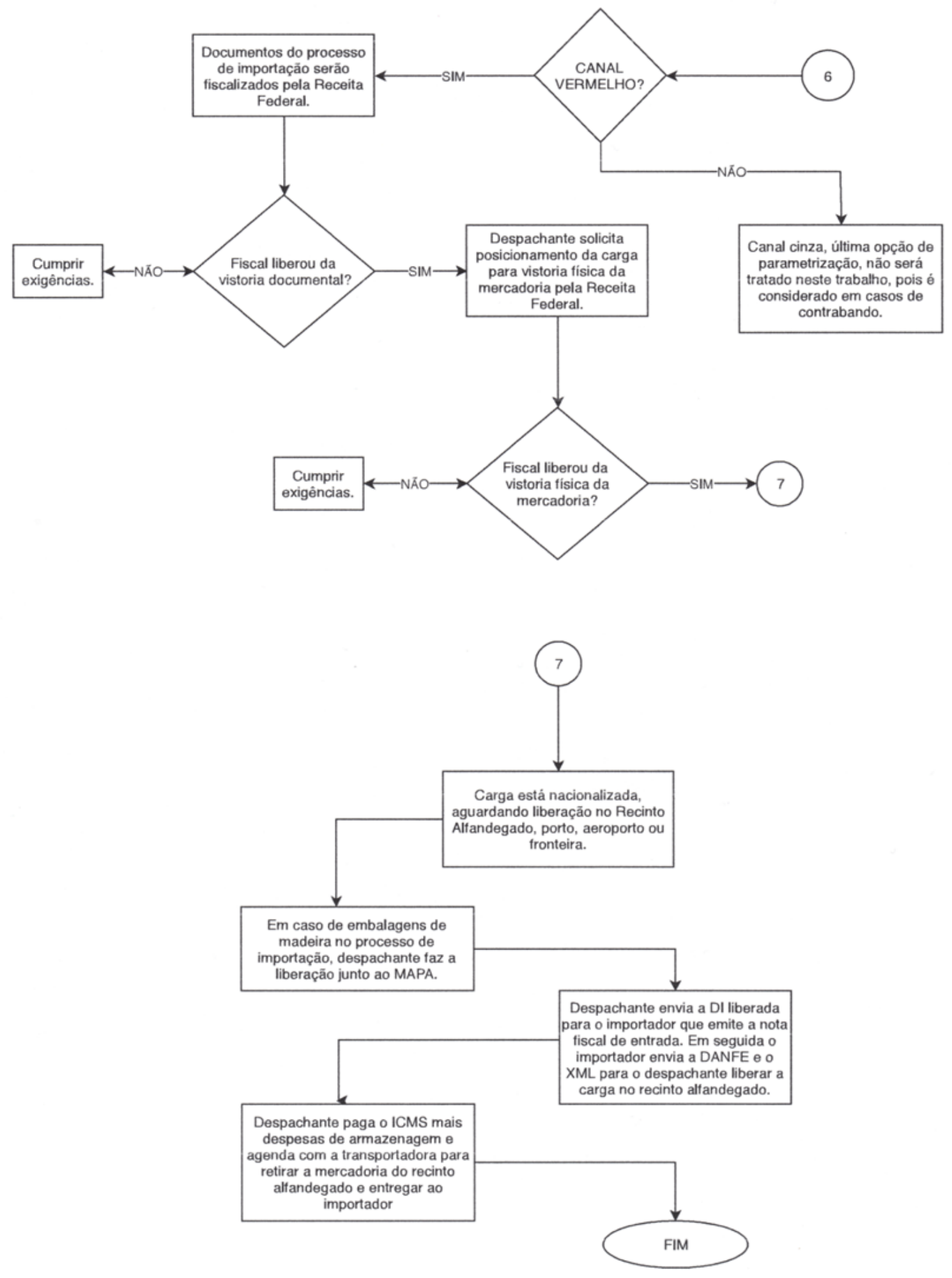

FONTE: O autor (2019)

FIGURA 2.3 - Fluxograma das etapas do processo de importação com processos decisórios, módulo 4. 
Para identificar as empresas importadoras onde foi aplicado o questionário, foi realizada uma pesquisa no Ministério do Desenvolvimento Indústria e Comércio (MDIC) em 2018, identificando 3.657 importadores no Estado do Paraná, dentre elas, indústrias, comércio, órgãos públicos, Associação de Pais e Amigos dos Excepcionais (APAE), hospitais, pessoas físicas, empresas em juízo, empresas sem "website" e filiais de empresas importadoras de outros Estados (MDIC, 2019).

Para validação das empresas listadas no MDIC, foi adquirido o cadastro de empresas importadoras registradas na FIEP referente ao ano de 2018. As empresas pesquisadas inicialmente no MDIC, após cruzamento das informações com o cadastro da FIEP, foram revalidadas (FIEP, 2019).

Do total de 3.657 empresas importadoras do Estado do Paraná, foram consideradas válidas 1.410 empresas matrizes ativas de cunho comercial ou industrial desconsiderando -se as demais empresas.

O retorno do questionário foi de 171 empresas, com respostas recebidas no período de 04.11 .2018 a 28.01.2019, totalizando $12,12 \%$ do total de empresas válidas, sendo a capacidade dos importadores a partir de 1 até acima de 100 processos de importação no ano de 2018.

Para complementar o questionário, foi feita uma entrevista com os despachantes aduaneiros como complemento das informações do questionário para obtenção de informações pelos prestadores de serviço, pois são os despachantes aduaneiros que operam as importações nas aduanas e tem a realidade operacional no seu dia a dia.

Para obtenção de um número relevante de entrevistas, foi realizada uma pesquisa no "site" do Ministério do Desenvolvimento Indústria e Comércio (MDIC) e foram localizados 1.012 despachantes aduaneiros no Estado do Paraná, em 2018 (RECEITA FEDERAL, 2019 b).

Os despachantes aduaneiros, por sua vez, trabalham em Comissárias de desembaraço aduaneiro, que são empresas que contratam despachantes aduaneiros para atender os importadores. Para que fosse identificado os despachantes aduaneiros em atividade, foi feita uma pesquisa da Classificação Nacional de Atividades Econômicas (CNAE) no 5250801 para Comissárias de despachos e n5250802 para Atividades de Despachante Aduaneiro, na Associação Comercial do Paraná, e foram identificadas 80 empresas ativas no ano de 2018.

As entrevistas foram realizadas com oito Comissárias de desembaraço, totalizando $10 \%$ das empresas ativas e responsáveis pelas importações de 418 importadores em 2018 
no Estado do Paraná.

Em ambas as pesquisas foi identificado que $82,45 \%$ das empresas tiveram canais vermelhos em 2018. Canal vermelho é quando existe a vistoria da importação pela Receita Federal. E para todos os canais vermelhos indicados, foram obtidos os prazos em dias corridos para liberação de uma importação nos recintos alfandegados do Estado do Paraná para conforme (Tabela 1).

Tabela 1. Dias para liberação de uma importação em canal vermelho por recinto alfandegado.

\begin{tabular}{lccccccccccc}
\hline $\begin{array}{l}\text { Recintos } \\
\text { alfandegados }\end{array}$ & $\begin{array}{c}\mathbf{3} \\
\text { dias }\end{array}$ & $\begin{array}{c}\mathbf{6} \\
\text { dias }\end{array}$ & $\begin{array}{c}\mathbf{9} \\
\text { dias }\end{array}$ & $\begin{array}{c}\mathbf{1 2} \\
\text { dias }\end{array}$ & $\begin{array}{c}\mathbf{1 5} \\
\text { dias }\end{array}$ & $\begin{array}{c}\mathbf{1 8} \\
\text { dias }\end{array}$ & $\begin{array}{c}\mathbf{2 1} \\
\text { dias }\end{array}$ & $\begin{array}{c}\mathbf{2 4} \\
\text { dias }\end{array}$ & $\begin{array}{c}\mathbf{2 7} \\
\text { dias }\end{array}$ & $\begin{array}{c}\mathbf{3 0} \\
\text { dias }\end{array}$ & Total \\
\hline Aeroporto & 7 & 8 & 17 & 13 & 22 & 4 & 9 & 13 & 5 & 11 & 109 \\
Fronteiras & 3 & 8 & 9 & 6 & 8 & 2 & 2 & 9 & 2 & 7 & 56 \\
Portos & 1 & 3 & 2 & 8 & 16 & 5 & 17 & 24 & 7 & 37 & 120 \\
Portos secos & 2 & 4 & 9 & 6 & 9 & 5 & 4 & 11 & 3 & 6 & 59 \\
\hline FONTE: O autor (2019) & & & & & & & & &
\end{tabular}

Além dos prazos, os importadores e os despachantes aduaneiros identificaram os 3 principais itens críticos de uma importação, por ordem de importância conforme abaixo:

1.Classificação fiscal das mercadorias;

2.Descrição das mercadorias;

3.Documentação.

Outro dado relevante foi que 101 empresas apontaram retificar as informações prestadas à Receita Federal, em processos de canal vermelho, com relação aos 3 fatores acima, totalizando $59 \%$ do total das empresas que tiveram canal vermelho em 2018. Para que seja possível um melhor entendimento de cada um dos 3 fatores, segue abaixo a descrição do risco e como cada fator é aplicado no processo de importação:

1. Classificação fiscal das mercadorias: é um código de 8 números que determina o grupo fiscal de cada produto e estipula o percentual de impostos para a importação. Conhecido também como Nomenclatura Comum do Mercosul (NCM). A NCM é utilizada nos documentos de importação e é declarada na 
Declaração de Importação (DI) no ato de registro da importação pelo despachante aduaneiro. Além do processo de importação, a NCM se estende à Nota Fiscal Eletrônica de entrada e consequentemente no estoque da empresa, qualidade, contabilidade e departamento financeiro.

2. Descrição das mercadorias: é a forma como o importador descreve o produto a ser importado. Essa descrição é declarada pelo despachante aduaneiro na DI e é uma descrição complementar da NCM, já que a NCM também possui sua descrição. A descrição da NCM é possível encontrar nas Notas Explicativas do Sistema Harmonizado (NESH).

3. Documentação: são os documentos exigidos pela Receita Federal conforme regulamento aduaneiro Decreto $n^{0}$ 6.759, de 5 de fevereiro de 2009 para a liberação alfandegária de importação.

Identificado os pontos críticos, foi desenvolvida a matriz de probabilidade e impacto com o intuito de possibilitar a avaliação de um projeto de importação por níveis de riscos no setor farmacêutico, laboratorial e hospitalar, representado por $11,17 \%$ das empresas que responderam o questionário.

Tabela 2. Matriz de probabilidade e impacto de riscos.

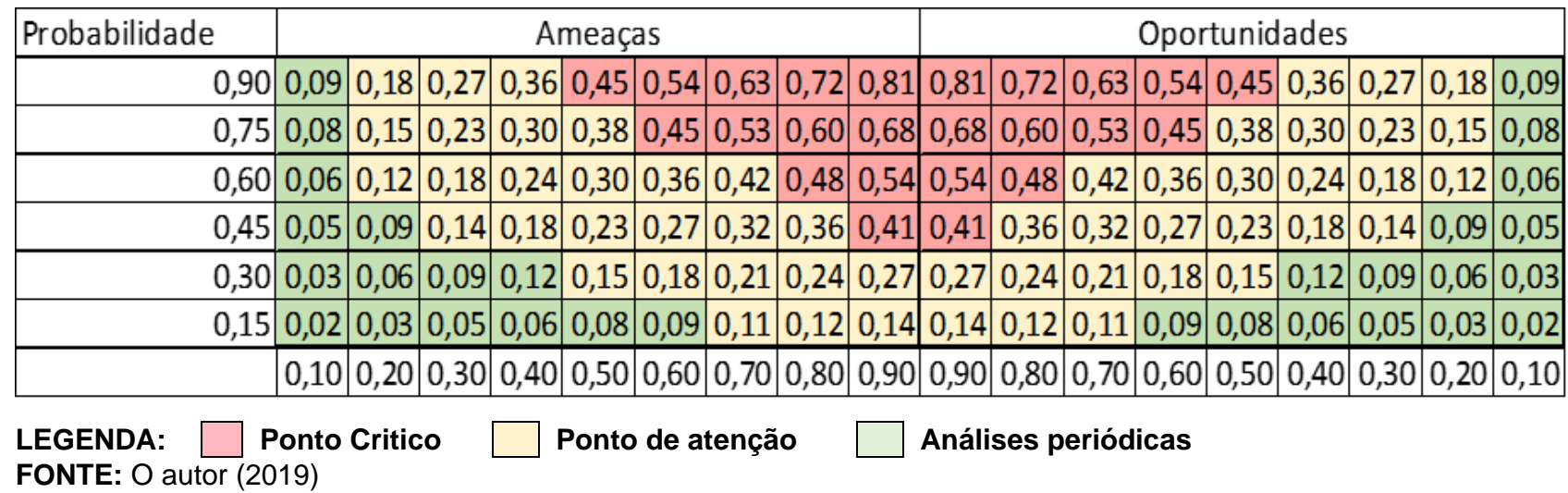

A pontuação da matriz de probabilidade e impacto de riscos foram definidos pela análise da probabilidade de uma oportunidade ou risco ocorrer dentro de uma etapa do processo de importação e o seu impacto nos custos e prazos, determinando assim 3 situações de verificação: análises periódicas, ponto de atenção e ponto crítico. 


\section{CONCLUSÕES}

A gestão de riscos na importação de insumos farmacêuticos é de suma importância para que importadores possam reduzir seus custos e prazos. As empresas relataram dificuldade na identificação das leis e nas etapas de execução, tornando-se necessário um fluxograma com processos decisórios.

As empresas e despachantes aduaneiros também apontaram os três principais pontos críticos nos projetos de importação, que se avaliados de forma correta, reduzem os custos e prazos nas importações de insumos farmacêuticos.

\section{REFERÊNCIAS}

BANCO MUNDIAL. Gross Domestic product, 2019. Disponível em: <https://databank. worldbank.org/data/download/gdp.pdf>. Acesso em: 13 ago. 2019.

COMEXSTAT. Exportação e Importação geral. 2019. Disponível em: <http://comexstat. mdic.gov.br/pt/geral>. Acesso em: 05 ago.2019.

FIEP, Federação das Indústrias do Estado do Paraná. Cadastro das Indústrias do Paraná 2018. 2019. Disponível em:<http://www.fiepr.org.br/cinpr/servicoscin/inteligência-comercial/ cadastro-das-industrias-do-parana-2016-1-24594-240164.shtml>. Acesso em: 15 out. 2019.

MDIC - Ministério do Desenvolvimento, Indústria e Comércio Exterior. Empresas brasileiras exportadoras e importadoras. 2019d. Disponível em: <http://www.mdic.gov.br/index.php/ comercio-exterior/estatisticas-de-comercio-exterior/empresas-brasileiras-exportadorase-importadoras>. Acesso em: 19 out. 2019.

OLIVEIRA, U.R. The ISO 31000 standard in supply chain risk management. Journal of Cleaner Production. 151, p. 616 - 633. Elsevier, 2017.

PINHEIRO, et. al. Pesquisa de mercado. Rio de Janeiro: Editora FGV. p.56, 2011 a.

PINHEIRO, et. al. Pesquisa de mercado. Rio de Janeiro: Editora FGV. p.88, 2011 b. 
PMI - PROJECT MANAGEMENT INSTITUTE. Guia PMBOK® - Project Management Body of Knowledge. 6. ed. Pensilvania:Project management standard guide. p. 395. 2017.

RECEITA FEDERAL. Despacho de Importação -DI. 2015a. Disponível em: Disponível em: <http://receita.economia.gov.br/orientacao/aduaneira/manuais/despacho-de-importacao/ topicos-1/despacho-de-importacao/etapas-do-despacho-aduaneiro-de-importacao/despachode-importacao-di> Acesso em: 21 nov. 2018.

RECEITA FEDERAL. Despachantes aduaneiros. 2019e. Disponível em < http://receita.economia.gov.br/orientacao/aduaneira/importacao-e-exportacao/habilitacao/ despachantes-aduaneiros>. Acesso em: 12 maio 2019.

VANGRASSTEK, C. The History and Future of the world trade organization, ISBN 978-92870-3871-5. World Trade Organization, Geneva, p. 8, 2013. 